\section{Acknowledgments}

This work was supported by grants through the Deutsche

Forschungsgemeinschaft (SFB 506 and HO1596), the Deutsche Krebshilfe, Mildred-Scheel-Stiftung, e.V. and the Bundesministerium für Bildung und Forschung.

1. Riddell, S.R. \& Greenberg, P.D. Principles for adoptive T-cell therapy of human viral diseases. Annu. Rev. Immunol. 13, 545-586 (1995).

2. Yee, C, Riddell S.R. \& Greenberg, P.D. Prospects for adoptive T-cell therapy. Curr. Opin. Immunol. 9, 702-708 (1997).

3. Kolb, H.J. et al. Graft-versus-leukemia effect of donor lymphocyte transfusions in marrow grafted patients. European group for blood and marrow transplantation working party chronic leukemia. Blood 86, 2041-2050 (1995).

4. Altman, J.D. et al. Phenotypic analysis of antigen-specific T lymphocytes. Science 274, 94-96 (1996).

5. Romero, P. et al. Ex vivo staining of metastatic lymph nodes by class I major histocompatibility complex tetramers reveals high numbers of antigen-experienced tumor-specific cytolytic T lymphocytes. J. Exp. Med. 188, 1641-1650 (1998).

6. Pardoll, D.M. \& Topalin, S.L. The role of CD4 $4^{+}$T-cell responses in antitumor immunity. Curr. Opin. Immunol. 10, 588-594 (1998).

7. Barth, R.J., Mule, J.J., Spiess, J. \& Rosenberg, S.A. Interferon $\gamma$ and tumor necrosis factor have a role in tumor regressions mediated by murine $\mathrm{CD} 8^{+}$tumor-infiltrating lymphocytes. J. Exp. Med. 176, 647-652 (1991).

8. Qin, Z. \& Blankenstein, T. CD4 ${ }^{+}$T cell-mediated tumor rejection involves inhibition of angiogenesis which is dependent on IFN- $\gamma$ receptor expression by nonhematopoietic cells. Immunity 12, 677-686 (2000).

9. Brosterhuis, H. et al. Enrichment and detection of live antigen-specific $\mathrm{CD} 4^{+}$and CD8 ${ }^{+}$T cells based on cytokine secretion. Eur. J. Immunol. 12, 4053-4059 (1999).

10. Riddell, S.R. \& Greenberg, P.D. The use of anti-CD3 and anti-CD28 monoclonal antibodies to clone and expand human antigen-specific T cells. J. Immunol. Methods 128, 189-201 (1990).

11. Huang, A.Y.C. et al. The immunodominant major histocompatibility complex class I-restricted antigen of a murine colon tumor derives from an endogeneous retroviral gene product. Proc. Natl. Acad. Sci. USA 93, 9730-9735 (1996).

12. Slifka, M.K., Rodriquez, F. \& Whitton, L. Rapid on/off cycling of cytokine production by virus-specific CD8 ${ }^{+}$T cells. Nature 401, 76-79 (1999).

13. Chiodoni, C. et al. Dendritic cells infiltrating tumors cotransduced with GM-CSF and CD40 ligand genes take up and present endogenous tumor-associated antigens, and prime naive mice for a cytotoxic T lymphocyte response. J. Exp. Med. 190, 125-133 (1999).

14. Schendel, D.J. et al. Cellular and molecular analyses of major histocompatibility complex (MHC) restricted and non-MHC-restricted effector cells recognizing renal cell carcinomas: Problems and perspectives for immunotherapy. J. Mol. Med. 75, 400-413 (1997).

15. Schendel, D.J. et al. Tumor-specific lysis of human renal cell carcinomas by tumorinfiltrating lymphocytes. I. HLA-A2-restricted recognition of autologous and allogeneic tumor lines. J. Immunol. 151, 4209-4220 (1993).

16. Jantzer, P. \& Schendel, D.J. Human renal cell carcinoma antigen-specific CTLs: Antigen-driven selection and long-term persistence in vivo. Cancer Res. 58, 3078-3086 (1998)

17. Pohla, H. et al. Allogeneic vaccination for renal cell carcinoma: Development and monitoring. Bone Marrow Transpl. 25, 83-87 (2000).

18. Schendel, D. et al. Expression of B7.1 (CD80) in a renal cell carcinoma line allows expansion of tumor-associated cytotoxic T lymphocytes in the presence of an alloresponse. Gene Therapy 7, 2007-2014 (2000)

19. Bernhard, H. et al. Cellular immune response to human renal-cell carcinomas: Definition of a common antigen recognized by HLA-A2 restricted cytotoxic T-lymphocyte (CTL) clones. Int. J. Cancer 59, 837-842 (1994).

20. Hoffmann, D.M., Gitlitz, BJ., Belldegrun, A. \& Figlin, R.A. Adoptive cellular therapy. Semin. Oncol. 27, 221-233 (2000).

\title{
ON THE MARKET
}

\section{MEDIA MEDLEY}

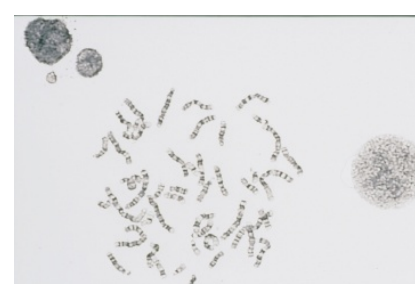

Taking it to the max with Gibco's

MarrowMax bone marrow medium.

MarrowMax bone marrow medium is a specialty medium, developed under the Gibco brand by Invitrogen, which is designed specifically to support bone marrow and peripheral blood cell culture for in vitro cytogenetic analysis. The product contains a stromal cell-conditioned medium composed of a blend of hematopoietic factors to promote optimal cell growth. Complete and ready to use, MarrowMax is fully supplemented with serum, antibiotics and L-glutamine. The medium requires no additional supplementation, thus reducing the chance of contamination and saving on preparation time, says Gibco.

Tel. (+1) 716-774-6700

www.invitrogen.com

Sigma-Aldrich has launched the Stemline methylcellulose media line for optimized hematopoietic CFU (colony forming units) assay results. The product line features eight new media for human and mouse cultures, and formulations with and without growth factors. Stemline media are performance-tested with normal human progenitors (12 to 16-day assay) or normal mouse bone marrow cells (7 to 10-day assay) to ensure consistent results. When appropriately supplemented with cytokines, Stemline media will support the growth of granulocyte colonies, macrophage colonies, granulocyte/macrophage colonies, erythroid colonies and pluripotent mixed colonies.

Tel. (+1) 314-771-5765

Fax (+1) 314-771-5757

www.sigma-aldrich.com

\section{ANTIBODIES}

Biotinylated anti-green fluorescent protein (GFP) for use in western blot detection of GFP or GFP-containing fusion (chimeric) proteins is now available from Vector Laboratories. Raised in goat and affinitypurified, this polyclonal antibody binds to wild-type, recombinant and modified forms of Aequorea victoria GFP. Its use in western blots has been optimized with the Vectastain ABC-AmP kit, an amplified alkaline phosphatase-based $\mathrm{ABC}$ complex with chromogenic or chemiluminescent/fluorescent detection options provided. The biotinylated anti-GFP antibody is also compatible with any avidin- or streptavidin-based detection system.

Tel. (+1) 650-697-3600

Fax $(+1)$ 650-697-0339

\section{GOING WITH THE FLOW}

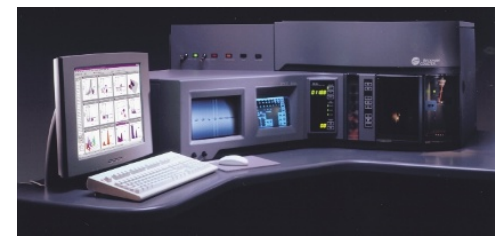

MultiComp accessory improves multi-color analysis on Coulter Epics Altra flow cytometers.

Designed for use with Beckman Coulter's Epics Altra flow cytometer, the MultiComp accessory is said to dramatically improve multi-color analysis for laboratories involved in immunobiology, cell physiology, molecular biology, genetics, microbiology and other research applications that use flow cytometry. The new flow cytometry accessory incorporates hardware and Expo 32 software to provide researchers with a sophisticated method of color compensation. This technology, called inverted matrix compensation, is designed to help researchers set up color compensation more precisely on multiple cell populations. In addition, the technology enables researchers to more easily perform a variety of single- or multi-laser applications, including applications requiring either air- or water-cooled lasers, or both.

Tel. (+1) 800-352-3433

www.beckmancoulter.com 